\title{
Article
}

\section{The VCDQ - a Questionnaire for Symptom Monitoring in Vocal Cord Dysfunction}

Fowler, Stephen J., Thurston, Andrew, Chesworth, Brigit, Cheng, Vinton, Constantinou, Panayiotis, Vyas, Aashish, Lillie, Siobhan and Haines, Jemma

Available at http://clok.uclan.ac.uk/12036/

Fowler, Stephen J., Thurston, Andrew, Chesworth, Brigit ORCID: 0000-00017936-5536, Cheng, Vinton, Constantinou, Panayiotis, Vyas, Aashish, Lillie, Siobhan and Haines, Jemma (2015) The VCDQ - a Questionnaire for Symptom Monitoring in Vocal Cord Dysfunction. Clinical \& Experimental Allergy . n/a-n/a. ISSN 09547894

It is advisable to refer to the publisher's version if you intend to cite from the work. http://dx.doi.org/10.1111/cea.12550

For more information about UCLan's research in this area go to http://www.uclan.ac.uk/researchgroups/ and search for <name of research Group>.

For information about Research generally at UCLan please go to http://www.uclan.ac.uk/research/

All outputs in CLoK are protected by Intellectual Property Rights law, including Copyright law. Copyright, IPR and Moral Rights for the works on this site are retained by the individual authors and/or other copyright owners. Terms and conditions for use of this material are defined in the policies page. 
Article Type: Original Article-Asthma and Rhinitis

\title{
The VCDQ - a Questionnaire for Symptom Monitoring in Vocal Cord Dysfunction
}

\author{
Stephen J. Fowler ${ }^{1,2}$, Andrew Thurston ${ }^{1}$, Brigit Chesworth ${ }^{1}$, Vinton Cheng ${ }^{1}$, Panayiotis \\ Constantinou ${ }^{1}$, Aashish Vyas ${ }^{1}$, Siobhan Lillie ${ }^{1}$, Jemma Haines ${ }^{1}$
}

\section{Affiliations:}

1. Respiratory Medicine, Lancashire Teaching Hospitals NHS Foundation Trust, Preston, UK

2. The University of Manchester; Manchester Academic Health Science Centre; NIHR South Manchester Respiratory and Allergy Clinical Research Facility, University Hospital of South Manchester, Manchester, UK

Correspondence: $\quad$ Stephen J Fowler,

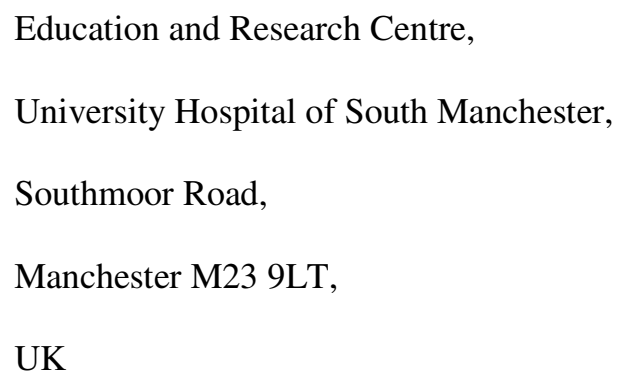

Email: stephen.fowler@manchester.ac.uk

This article has been accepted for publication and undergone full peer review but has not been through the copyediting, typesetting, pagination and proofreading process, which may lead to differences between this version and the Version of Record. Please cite this article as doi: 10.1111/cea.12550

This article is protected by copyright. All rights reserved. 
ABSTRACT

Background: Vocal Cord Dysfunction (VCD) typically involves abnormal adduction of the vocal cords during inspiration, mimics the symptoms of asthma and leads to the prescription of ineffective medications.

Objective: We aimed to develop a clinical tool to monitor symptoms and response to treatment in confirmed VCD.

Methods: We collated symptoms of VCD from focus groups comprising patients and healthcareprofessionals; phrases describing these symptoms were assessed for face validity and internal correlation, and rated for importance. The resultant 12 item questionnaire (VCDQ) rated the impact of each on a 5-point Likert scale (total score range 12 to 60), and was tested for reliability, concurrent validity and performance in 31 patients with endoscopically confirmed VCD ( \pm asthma), 29 asthmatics with no history of VCD, and 14 healthy controls. We assessed response to speech and language therapy and the minimal important difference by measuring the VCDQ pre- and posttherapy in a 20 new patients.

Results: The VCDQ had excellent test-retest reliability, and differentiated VCD versus healthy (Mann-Whitney test: $\mathrm{z}=-5.390, \mathrm{P}<0.001)$ and asthma $(\mathrm{z}=-5.730, \mathrm{p}<0.001)$. All patients improved post-therapy, assessed both by a global rating of change score (GRCS) and by the VCDQ [median (IQR) score pre-therapy $50.5(48.0-54.8)$, post therapy $35.0(29.3-41.8), \mathrm{p}<0.001]$. The minimal important difference in the VCDQ associated with a rating of "minimally better" on the GRCS was 4 points.

Conclusions and Clinical Relevance: The VCDQ is a valid and responsive tool suitable for measuring changes in symptoms in patients with VCD. It also gives insight into which symptoms are important to patients, and could guide future therapy refinements. Future assessments of novel therapies for this condition should use an appropriately validated tool such as the VCDQ to measure response.

This article is protected by copyright. All rights reserved. 


\section{INTRODUCTION}

Vocal cord dysfunction (VCD) manifests as abnormal adduction of the vocal cords during breathing, resulting in episodes of extrathoracic airway obstruction and breathlessness [1]. Presenting symptoms closely resemble those of asthma, with intermittent wheeze and dyspnoea often following exposure to triggers such as exercise [2] or pollutants [3]. Therefore the majority of sufferers receive an initial diagnosis of asthma [4]. However, VCD will not respond to asthma medication, although often therapy is stepped up progressively resulting in treatment with high dose inhaled and oral steroids without benefit, but significant risk of adverse effects [5]. There is also frequent use of emergency services among VCD sufferers with one retrospective study [4] reporting ten presentations to the emergency department and six hospital admissions per patient per year, and another that VCD patients had significantly more hospital visits than a comparator group with moderate persistent asthma [6]. The same study also reported that on average asthma had been misdiagnosed for five years before a correct diagnosis of VCD was made. Severe acute presentations of VCD can even result in tracheal intubation or tracheotomy [7]. Despite this, the term VCD is only mentioned once in the British Thoracic Society asthma guidelines [8] and only four times in the joint European Respiratory Society / American Thoracic Society asthma guidelines [9].

Vocal cord dysfunction can present at any age and appears to be more common in females [10]. It has been thought to be a relatively rare condition and does not feature prominently in medical teaching programmes. It is likely therefore that in general the clinical index of suspicion is low. One study reviewed 120 cases of exertional dyspnoea and found that VCD was the cause in $12 \%$ [11], suggesting it may be more prevalent than generally appreciated. The pathophysiology of VCD is poorly understood and sometimes considered to be mainly a psychological disorder with labels used such as "Munchausen's Stridor" and "factitious asthma" [12]. Whilst psychological factors undoubtedly sometimes play a role in the presentation of $\mathrm{VCD}$, there is now greater recognition of other contributing factors, such as laryngopharyngeal reflux and underlying lung and nasal disease $[13,14]$.

This article is protected by copyright. All rights reserved. 
The gold standard for diagnosis of VCD requires direct visualisation of paradoxical vocal cord movement on laryngoscopy whilst the patient is symptomatic [15]. This requires specialist skills and knowledge that is not currently widely available. A high index of suspicion is required to identify patients with the condition who require further investigation. There has been no systematic investigation to date of the symptoms reported by patients with $\mathrm{VCD}$, and how these might differ from asthma. Management of VCD involves a multi-disciplinary approach and should include treating any identifiable cause (e.g. gastro-oesophageal reflux disease), avoiding triggers, specific psychological counselling, and speech and language therapy. The latter involves techniques to focus on expiration and diaphragmatic breathing, and is considered the main treatment for chronic VCD [16]. We have performed a qualitative study investigating symptoms in VCD with the aim of monitoring response to these treatment interventions.

\section{METHODS}

Adult patients with endoscopically proven VCD were recruited from our specialist airways clinic. The group contained patients both with VCD as the sole diagnosis and others with both VCD and a clinical diagnosis of asthma. All patients were awaiting or currently undergoing treatment with speech and language therapy. Patients with a physician's diagnosis of asthma but without VCD were recruited from the same clinic. Healthy controls, with no history of respiratory disease, were recruited from the community. All participants gave their written informed consent before inclusion and approval for this study was obtained from the North West 12 Regional Ethics Committee (Lancaster).

The VCD questionnaire (VCDQ) was developed using a three-stage approach as employed by previous respiratory symptom questionnaires [17]. Stage I - item generation, Stage II - item reduction (A - face validity, B - importance, C - correlation), and Stage III - validation (A - test-retest reliability, $\mathrm{B}$ - concurrent validity, $\mathrm{C}$ - performance). The intention was to produce a questionnaire comprising a broad range of symptoms that could be used to monitor longitudinal changes in the condition.

This article is protected by copyright. All rights reserved. 


\section{Stage I: Item Generation}

An initial literature search was carried out which revealed no previous publications relating to VCD specific symptom questionnaires, and information from the VCD literature was used to aid item generation. Two sets of focus groups were held, one including nine healthcare professionals (a mix of specialist and general respiratory physicians and allied healthcare professionals) and the other fifteen patients with proven VCD, in order to generate a long list of statements relating to symptoms and quality of life issues.

\section{Stage II: Item Reduction}

Stage IIA (Face Validity): The list of statements was given to ten participants with a diagnosis of VCD initially to ask if each item made sense. Items were removed if their meaning was not clear to two or more of the group.

Stage IIB (Importance): The importance of each item on the draft questionnaire was rated by the same ten patients on a five point Likert scale $(1==$ no importance, $5=$ very important $)$. An item was deemed to be of low importance and removed from the questionnaire if $>40 \%$ of the participants rated it as three or less.

Stage IIC (Correlation): The response to each item on the draft questionnaire was rated on a five point Likert scale $(1=$ strongly disagree, $5=$ strongly agree $)$. This was then given to 16 treatmentnaïve VCD patients. A correlation matrix including all the questions was produced and where the responses to two questions showed $>75 \%$ correlation the one previously rated with the lowest importance was removed. The remaining statements comprised the long version VCDQ which underwent further validation as outlined below

\section{Stage III: Preliminary Validation}

Stage IIIA (Test-Retest reliability): Eight of the VCD patients were retested with the VCDQ after a minimum of one week.

This article is protected by copyright. All rights reserved. 
Stage IIIB (Concurrent Validity): There are no other specific VCD questionnaires in use that we are aware of but prior to the development of the VCDQ we had devised a VCD visual analogue scale (VAS) for use in clinical practice as part of the initial assessment, and we used this as well as the St. George's Respiratory Questionnaire [18] (SGRQ, with kind permission of St. George's University of London Medical School) to investigate concurrent validity. Both the VAS and SGRQ were given to 15 participants with VCD along with the VCDQ.

Stage III C (Performance): The VCDQ was given to a new cohort of patients with VCD (including some with both VCD and asthma), asthma alone, and healthy controls, in order to compare response across these three groups. We then assessed the questionnaire's responsiveness to change by measuring it in a new group of VCD patients before and after a course of speech and language therapy. No other changes to treatment (e.g. where there was co-existent respiratory disease) were made during the period of speech and language therapy. At the same time we asked patients to complete a Global Rating of Change Score (GRCS), a 7-point self-completed scale whereby patients rate how much their condition has changed over the treatment period, with negative scores $(-3,-2,-1)$ associated with deterioration (very much, much or minimally worse), 0 representing no change and positive scores $(3,2,1)$ associated with improvements (very much, much, minimally better). We were thus able to estimate the minimal important difference in the VCDQ that was associated with an important improvement in patient symptoms.

\section{Statistical analysis}

Data analysis was performed using SPSS 15 (SPSS Inc. Chicago, USA). Correlations between the individual items of the questionnaire, between the VCDQ and the VAS, SGRQ total, and the three individual domains of the SGRQ were assessed using Spearman's rank coefficient (expressed as Interclass Correlation Coefficient, ICC, which compares groups of data rather than paired data). The Mann-Whitney U Test was used to compare the VCD group with both the asthma group and the healthy controls, and Wilcoxon's Signed Rack Test for paired pre- and post-treatment data

This article is protected by copyright. All rights reserved. 


\section{RESULTS}

Ninety participants took part in total: 47 with VCD, including 24 with coexistent lung disease (20 with asthma, two with bronchiectasis and two with chronic obstructive pulmonary disease); and 43 controls comprising 29 people with asthma and 14 healthy volunteers. All of the patients with VCD had the laryngoscopic appearance of classical inspiratory VCD, except for four who had mixed inspiratory and expiratory VCD, and one with expiratory VCD only. Demographic details for each group are shown in Table 1. There were significant between group differences in \% predicted FEV1 and FVC (ANOVA p < 0.05), and in gender $\left(\chi^{2} \mathrm{p}<0.05\right)$. All of the VCD patients had been referred to speech and language therapy (and were at various stages in their therapy) at the time of participation.

\section{Stage I: Item Generation}

The focus groups produced a long list of 17 items relating to the experience of VCD amongst the patient-volunteers and healthcare professionals.

\section{Stage II: Item Reduction}

Stage IIA (Face Validity): Four of the 10 participants with VCD rating each item felt that "I don't have pins \& needles and / or tingling during attacks" was too ambiguous and therefore this was removed from the long list. The question "My symptoms cause me to avoid certain situations" was also removed as the healthcare professionals felt that it was too vague.

Stage IIB (Importance): "My attacks can be triggered by stress" was removed from the VCDQ because of low importance leaving a 14 item draft.

Stage IIC (Correlation): There were two clear correlations seen within the 14 item VCDQ. "I feel frustrated that none of the treatments (e.g. inhaler) I'm given work" correlated with "I am frustrated that my symptoms have not been understood correctly" $(\mathrm{r}=0.75 ; \mathrm{p}<0.001)$. The latter was rated as more important previously and hence the former discarded. Secondly, "I'm aware of other specific triggers that cause attacks" correlated with "Moving away from the trigger and/or environment helps to relieve the attack" $(\mathrm{r}=0.76 ; \mathrm{p}<0.001)$. In this case the former was rated as the most important and

This article is protected by copyright. All rights reserved. 
so retained. This left the final 12 item version of the VCDQ (the 12 items are listed in table 2), with a possible total score range of 12 to 60

\section{Stage III: Preliminary Validation}

Stage IIIA (Test-Retest reliability): A strong correlation $(\mathrm{ICC}=0.937, \mathrm{p}=0.001)$ was found between the total VCDQ scores of the eight VCD patients who were retested, indicating very strong repeatability.

Stage IIIB (Concurrent Validity): The results of the concurrent validity with the SRGQ and the VAS are shown in table 3. The results of the VCDQ correlated strongly with the VAS, but with neither the total nor domain-scores of the SGRQ.

Stage III C (Performance):

The VCDQ total score was significantly different in the VCD groups versus both the healthy control group $(\mathrm{z}=-5.390, \mathrm{p}<0.001)$ and the asthma group $(\mathrm{z}=-5.730, \mathrm{p}<0.001)$. A histogram of total scores for each group is shown in figure 1. Within the VCD group there was no difference in VCDQ score between those with (median score 48, range 35 - 56) and without (median score 50, range $34-60$ ) coexistent lung disease.

The median (interquartile range) VCDQ score pre-treatment was $50.5(48.0$ - 54.8) points and posttreatment $35.0(29.3-41.8)$ points [median (interquartile range) difference $15.5(9.3-19.0)$ points, $\mathrm{p}$ $<0.001]$ When self-rating their response to therapy by the global rating of change score all 20 patients reported that their symptoms had improved: seven reported "minimally better", 10 "much better" and three "very much better". The minimal difference in VCDQ in those reporting "minimally better" was 4 and "much better" was 7.

This article is protected by copyright. All rights reserved. 


\section{DISCUSSION}

We have developed the first questionnaire for VCD based on patient-reported symptoms, and validated it in breathless patients with the condition. The VCDQ score was significantly higher in patients with VCD compared not only to healthy volunteers, but more importantly to those with asthma alone. The VCDQ was also responsive to changes in treatment, and we are able to suggest a minimal important difference for use in future therapeutic trials.

Although the prevalence is not yet known, systematic screening in patients with breathlessness does indicate VCD is a significant problem amongst patients presenting to the chest clinic [4, 11]. This is not reflected however in international guidelines; the British Thoracic Society asthma guideline for example mentions VCD only once [8]. Furthermore specialist diagnostic and treatment services are not widely available. A recent survey performed by us amongst healthcare professionals in the North West of England found that 113 of 126 had either "never heard of" or knew "little" about VCD (data on file). This level of knowledge was similar amongst the speech and language therapists surveyed with only 2 of 15 assessing that they had "good" knowledge of the condition, even though speech and language therapy is the cornerstone of management [16]. Understanding the sensations and symptoms that patients with VCD report is important to enable healthcare professionals to consider the diagnosis when appropriate in breathless patients.

We have validated the VCDQ in line with the process undertaken for previous respiratory questionnaires [17]. When patients were retested after a week the VCDQ produced correlating results showing that it has strong test-retest reliability. After a block of speech and language therapy, the score improved significantly in line with the patients' own rating of improvement. The VCDQ therefore has potential as a symptom monitoring tool, similar to the Leicester Cough Questionnaire [17] or SGRQ [18], and may be used to monitor response to speech and language therapy and any future treatment developments. The VCDQ scores correlated with our previously developed VAS but not with the SRGQ total or domain scores. This is perhaps not surprising; whilst the SRGQ was developed to explore symptoms in respiratory disease it has been tested only in lung disease and not

This article is protected by copyright. All rights reserved. 
upper airways disease such as VCD, and so would be expected to cover a different range of symptoms and concerns.

There are several methods for estimating the minimal important difference (MID) in a symptom-based questionnaire [19]. We have elected to assess a patient-reported outcome, the Global Rating of Change, in order to give an overview of the degree of change experienced by the patients. Such methods have previously been used for the validation of other respiratory scores [17]. The MID has been defined as the smallest difference that patients perceive to be beneficial [20] and hence previous studies have judged this to equate to a "minimal" improvement in global assessment or better. In our study this results in an MID of only 4, although we would also support the use of a higher cut-of 7 to indicate a greater improvement, corresponding with "much better" on the GRCS.

This questionnaire was not designed to be a diagnostic tool for VCD. The statements were drawn from patients' symptoms and experiences, and therefore may not be specific to the condition. However, the VCDQ may have future potential to be refined and developed into a diagnostic questionnaire, as patients with VCD scored much higher than both healthy controls and asthmatics. At 12 items its complexity make it less than ideal for everyday clinical use, and further testing and refinement will be required if it is to be considered as a diagnostic aid. The prevalence of VCD within the cohort was $41 \%(31 / 74)$, which is not a true representation of the real world prevalence or even that seen in within respiratory clinics (estimated at around $12 \%$ by Morris [10]). Further testing will be needed to obtain a sensitivity and specificity for VCD versus asthma (and other causes of breathlessness) where the prevalence of VCD is lower, such as in general respiratory clinics or primary care, as well as to account for other respiratory conditions, in particular upper airways diseases such as rhinosinusitis.

In summary, we have developed the first validated questionnaire for use in symptom monitoring in VCD. We would suggest such a tool is essential to guide future therapeutic refinements in this much 
neglected area. Furthermore, understanding the symptoms that patients with VCD experience will also aid in early recognition, and may lead to the development of a diagnostic aid.

\section{ACKNOWLEDGEMENTS}

The authors gratefully acknowledge the help of Sally Turner for help with identifying and recruiting volunteers for the study.

\section{FUNDING}

This study did not receive external funding.

\section{CONFLICT OF INTEREST STATEMENT}

The authors declare that they do not have any conflict of interest regarding this manuscript

\section{REFERENCES}

1. Kenn K, Balkissoon R. Vocal cord dysfunction: what do we know? Eur Respir J 2011; 37: $194-$ 200

2. Rundell KW, Spiering BA. Inspiratory stridor in elite athletes. Chest 2003; 123: 468-474.

3. Perkner JJ, Fennelly KP, Balkissoon R, Bartelson BB, Ruttenber AJ, Wood RP 2nd, Newman LS. Irritant-associated vocal cord dysfunction. J Occup Environ Med 1998; 40: 136-143.

4. Newman KB, Mason UG, Schmaling KB. Clinical features of vocal cord dysfunction. Am J Respir Crit Care Med 1995; 152: 1382-1386.

5. Forrest LA, Husein T, Husein O. Paradoxical vocal cord motion: classification and treatment. Laryngoscope 2012; 122:844-853.

6. Mitika J, Parker J. High Levels of Medical Utilization by Ambulatory patients with Vocal Cord Dysfunction as compared to Age- and Gender- matched Asthmatics. Chest 2006; 129:905-908

This article is protected by copyright. All rights reserved. 
7. Maillard I, Schweizer V, Broccard A, Duscher A, Liaudet L, Schaller MD. Use of botulinum toxin type A to avoid tracheal intubation or tracheostomy in severe paradoxical vocal cord movement. Chest 2000;118:874-877.

8. British guideline on the management of asthma. Thorax 2008;63 Suppl 4:iv1-121.

9. Bateman ED, Hurd SS, Barnes PJ, Bousquet J, Drazen JM, FitzGerald M, Gibson P, Ohta K, O'Byrne P, Pedersen SE, Pizzichini E, Sullivan SD, Wenzel SE, Zar HJ. Global strategy for asthma management and prevention: GINA executive summary. Eur Respir J 2008;31:143-178.

10. Morris MJ , Allan PF, Perkins PJ . Vocal cord dysfunction: etiologies and treatment . Clin Pulm Med. $2006 ; 13: 73-86$.

11. Morris MJ, Deal LE, Bean DR, Grbach VX, Morgan JA. Vocal cord dysfunction in patients with exertional dyspnoea. Chest 1999;116:1676-82.

12. Patterson R, Schatz M, Horton M. Munchausen's stridor: nonorganic laryngeal obstruction. Clin Allergy 1974; 4: 307-310.

13. Rolla G, Colagrande P, Scappaticci E, Bottomicca F, Magnano M, Brussino L, Dutto L, Bucca C. Damage of the pharyngeal mucosa and hyperresponsiveness of airway in sinusitis. J Allergy Clin Immunol 1997;100:52-7.

14. Yelken K, Yilmaz A, Guven M, Eyibilen A, Aladag I. Paradoxical vocal fold motion dysfunction in asthma patients. Respirology 2009; 14:729-733.

15. Gimenez LM, Zafra H. Vocal cord dysfunction: an update. Ann Allergy Asthma Immunol $2011 ; 106 ; 267-274$.

16. Gallivan GJ, Hoffman L, Gallivan KH. Episodic paroxysmal laryngospasm: voice and pulmonary function assessment and management. J Voice. 1996;10:93-105.

17. Birring SS, Purdon B, Carr AJ, Singh SJ, Morgan MDL, Pavord ID. Development of a symptom specific health status measure for patients with chronic cough: Leicester Cough Questionnaire (LCQ). Thorax 2003; 58: 339-343.

18. Jones PW, Quirk FH, Baveystock CM. The St George's Respiratory Questionnaire. Respir Med. 1991 Sep;85:25-31

This article is protected by copyright. All rights reserved. 
19. Gatchel RJ, Lurie JD, Mayer TG. Minimal Clinically Important Difference. Spine 2010; 35:1739-

43

20. Jaeschke R, Singer J, Guvatt GH. Measurement of health status. Ascertaining the minimal clinically important difference. Control Clin Trials 1989; 10: 407-15

Table 1: Demographic details of the included participants

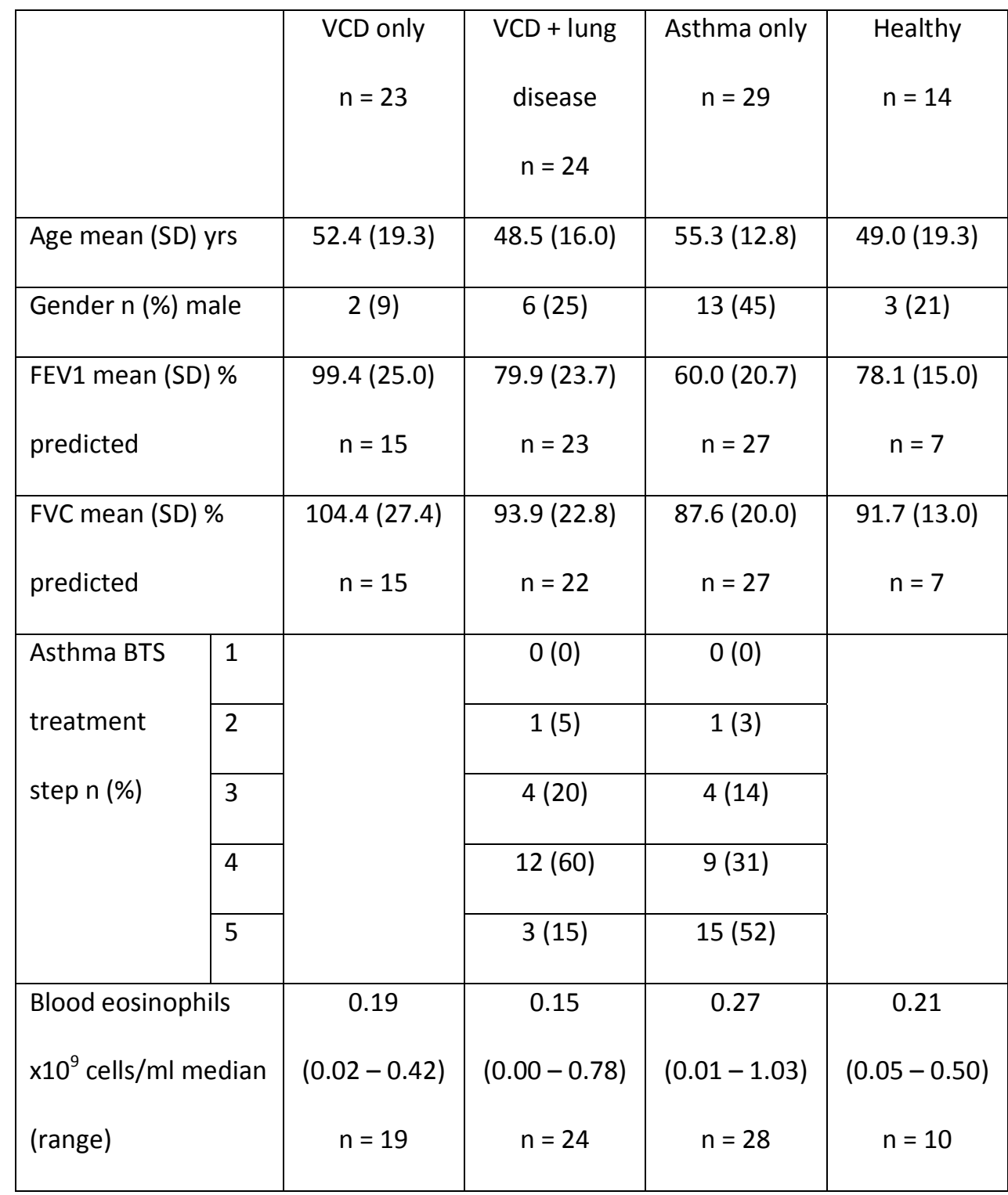

This article is protected by copyright. All rights reserved. 
Table 2: The 12-item Vocal Cord Dysfunction Questionnaire (VCDQ)

\begin{tabular}{|c|c|c|c|c|c|c|}
\hline Question & $\begin{array}{l}\text { Disagree } \\
\text { strongly }\end{array}$ & Disagree & $\begin{array}{l}\text { Neither } \\
\text { agree } \\
\text { nor } \\
\text { disagree }\end{array}$ & Agree & $\begin{array}{l}\text { Agree } \\
\text { Strongly }\end{array}$ & Score \\
\hline & 1 & 2 & 3 & 4 & 5 & \\
\hline \multicolumn{7}{|l|}{$\begin{array}{l}\text { 1.My symptoms are confined to } \\
\text { my throat / upper chest }\end{array}$} \\
\hline \multicolumn{7}{|c|}{$\begin{array}{l}\text { 2. I feel like I can't get breath past } \\
\text { a certain point in my throat / } \\
\text { upper chest because of restriction }\end{array}$} \\
\hline \multicolumn{7}{|l|}{$\begin{array}{l}\text { 3. My breathlessness is usually } \\
\text { worse when breathing in }\end{array}$} \\
\hline \multicolumn{7}{|l|}{$\begin{array}{l}\text { 4. My attacks typically come on } \\
\text { very suddenly }\end{array}$} \\
\hline \multicolumn{7}{|l|}{$\begin{array}{l}\text { 5. I feel that there is something in } \\
\text { my throat that I can't clear }\end{array}$} \\
\hline \multicolumn{7}{|l|}{$\begin{array}{l}\text { 6. My attacks are associated with } \\
\text { changes in my voice }\end{array}$} \\
\hline \multicolumn{7}{|l|}{$\begin{array}{l}\text { 7. My breathing can be noisy } \\
\text { during attacks }\end{array}$} \\
\hline \multicolumn{7}{|l|}{$\begin{array}{l}\text { 8. I'm aware of other specific } \\
\text { triggers that cause attacks }\end{array}$} \\
\hline \multicolumn{7}{|l|}{$\begin{array}{l}\text { 9. My symptoms are associated } \\
\text { with an ache or itch in my throat }\end{array}$} \\
\hline \multicolumn{7}{|l|}{$\begin{array}{l}\text { 10. I am frustrated that my } \\
\text { symptoms have not been } \\
\text { understood correctly }\end{array}$} \\
\hline \multicolumn{7}{|l|}{$\begin{array}{l}\text { 11. I am unable to tolerate any } \\
\text { light pressure around the neck, } \\
\text { e.g. tight clothes or bending the } \\
\text { neck }\end{array}$} \\
\hline \multicolumn{7}{|l|}{$\begin{array}{l}\text { 12. The attacks impact on my } \\
\text { social life }\end{array}$} \\
\hline TOTAL & & & & & & $(12-60)$ \\
\hline
\end{tabular}

This article is protected by copyright. All rights reserved. 
Table 3: Concurrent Validity - Comparing VCDQ with the SGRQ and VAS

\begin{tabular}{|c|c|c|c|c|c|}
\hline & \multicolumn{4}{|c|}{ SGRQ } & VAS Total \\
\cline { 2 - 5 } & Total & Symptoms & Activity & Impacts & \\
\cline { 2 - 5 } & & 0.258 & 0.465 & 0.466 & 0.739 \\
\hline Spearman's Rank & 0.414 & 0.353 & 0.081 & 0.080 & 0.001 \\
\hline
\end{tabular}

\section{Figure Legends}

Figure 1: Comparison of the 12 item VCDQ total scores between VCD and Non-VCD.

This article is protected by copyright. All rights reserved. 


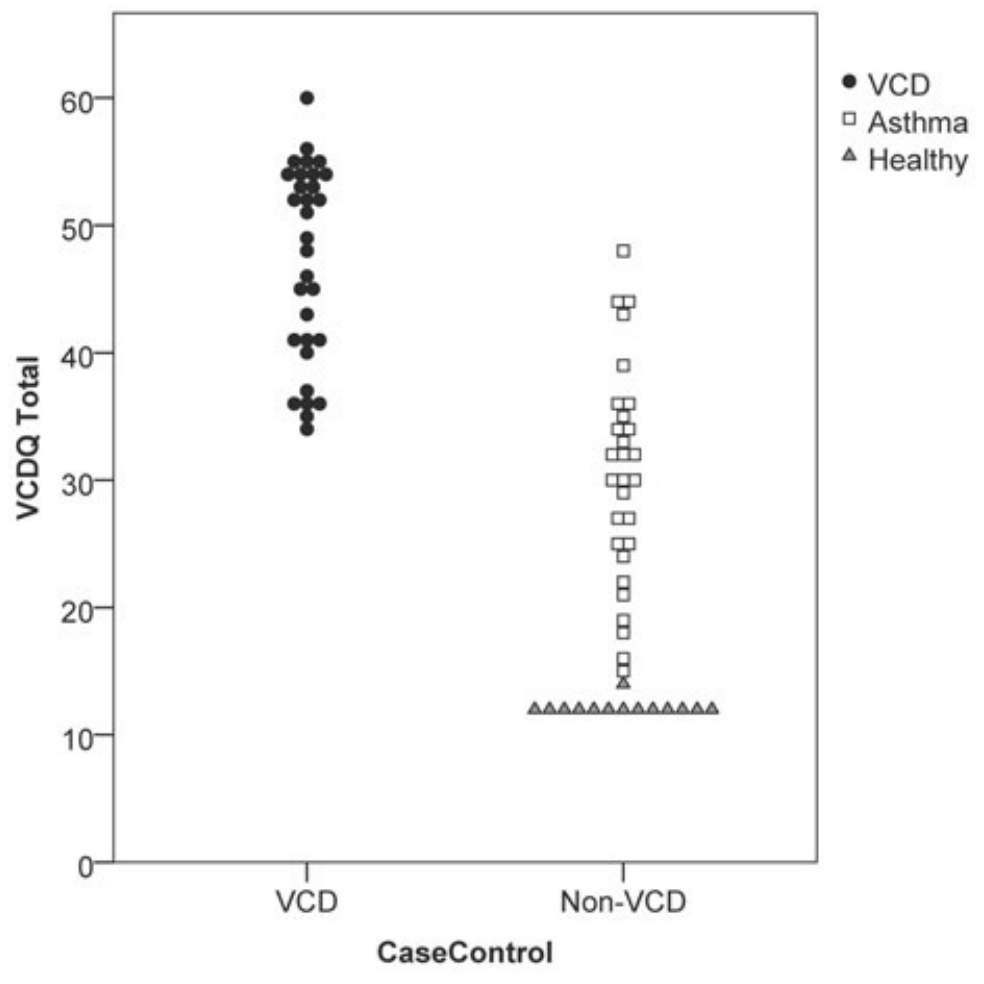

Page 1

This article is protected by copyright. All rights reserved. 